TO:

Mr. Edzo Tonkes

The Bernard von Leer Foundation

P.O. Box 82334

$2508 \mathrm{EH}$ The Hague, The Netherlands

FROM: Nancy Hatch Dupree

Duke University, Durham, N.C. U.S.A.

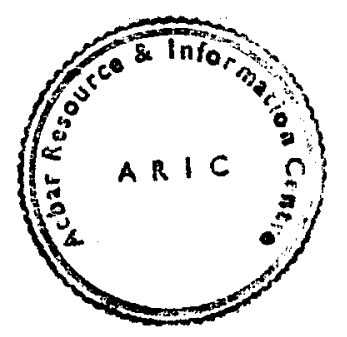

DATE: 29 January 1989

SUBJECT: Evaluation of Mothex-Child Centers Program for Afghan Refugees, Mangu, Pakistan (Ref. code:

X58(100)87-020; undertaken 5 thru 8 December 1988

Objectives for the MCC Program as stated in

the 27 July 1987 Letter of Grant envision the

1) development of community-based centers;

2) stimulation of the overall development of children, with special attention to health and interactions with peers;

3) restoration of the prime educator role of mothers through the stimulation of self-confidence and self-reliance;

4) development of para-professional early childhood case workers.

\title{
SUMMARY EVALUATION
}

The MCC at Kahi provides unique opportunities for child development and learning-through-play experiences.

In redesigning the program after women were excluded, the Coordinators have focused on a neglected aspect of rural development: approaches to preteens who play a major role in childrearing. Their findings will provide new data of value for reconstruction planning; a genuine contribution to Afghanistan studies.

Initial expectations concerning women were culturally unrealistic, but the new focus will give rise to different types of interactions which could benefit women.

Shortage of staff is'a problem.

The apparently limited number of regular participants vis-a-vis potential beneficiaries is not a problem. This project should be regarded as a pioneer research undertaking concerning the introduction of new concepts concerning early child development in Afghanistan.

If it is accepted as 'such', a móre complete data-recording system should be devised. 


\section{OBSERVATIONS}

The Facilities (Objective No. 1)

On arriving at the Kahi Mother-Child Center (MCC;

opened 24 April 1.988, one is impressed by its proportions and superior construction in comparison to the buildings accommodating the BHU (Basic Health Unit) and Women's Handicrafts and Self-Reliance Center located within the same walled complex. A less lofty edifice would have bien more appropriate, but the IRC Construction Unit determined the specifications.

The interior with its equally impressive spacious, high-ceilinged rooms leading one into the other for practical multi-purpose use are made light and cheery by many glazed windows. The decor, uncluttered and restful, is punctuated with colourful, locally purchased, red-plastic matting with cream-coloured floral motifs; multi-coloured lacquered cradles hang from the ceiling in a secluded back area without windows.

Piles of pastel cotton-stuffed quilts, art work by the children and a large map of Afghanistan adorn the walls along with shelves holding a welter of toys. Rubber balls and other toys overlow from locally-made wicker baskets stashed in corners and, in the center, low tables provide work space for children seated on the floor. Shoes, neatly stacked, sit on shelving flanking the single entrance door.

This Western observer's first impression was one of 
admiration for the superb locally-inspired decor executed simply, but with great style.

On attempting to analyze negative community reactions by looking at the MCC with the eyes of the rural Afghan population living in Kahi, however, these Western-oriented positive characteristics assumed certain liabilities.

Accounts differ regarding the degree to which Kahi's political and religious leaders were informed of the nature of MCC activities. Nevertheless, no matter what explanations may have been discussed, many concepts included in the MCC proposal, such as providing a "supportive environment" for "women to express themselves" and children to develop "psycho-socially," are far beyond the linderstanding of Kahi's mostly non-literate villagers. Probably the consensus of the male leadership simply assumed that the MCC would be some sort of an extension of IRC's health programme and therefore generally beneficial. Apparently this was the case with at least one initialiy supportive leader who now complains of being ostracized because of his earlier overt cooperation. The purposeful absence of clearly structured, focused activities permits dissidents to speculate about the real purpose of the program.

It is also highly probable that the MCC program has become a convenient pawn in the complex internal political dynamics of Kahi,. some of which is most certainly being orchestrated outside the community. If this is indeed the 
case, it is easy to see how the facility's attractiveness lends itself to ludicrous allegations.

Although modest even by Afghan urban terms, the pleasant colourful interior of the MCC was a novel sight for most of Kahi's residents. Why should children be provided such elaborate quarters? Surely more must be intended, said some, while intimating that the real goal might be to lure women for nefarious purposes or in order to pervent their minds with ideas about family planning. Similarly, a very reasonable request to prohibit photographs took on darker connotations when it was alluded that photos might be used in a scheme involving the sale of women to foreigners. It should be emphasized, however, that this particular accusation is not unique to Kahi. It is widely repeated, with variations, in attempts to impair the reputations of individuals and/or organizations.

Shoring up an unIslamic label for the MCC was the fact that the opening took place during Ramazan, the holy month of fasting, with festive displays and distribution of sweets.

Although the attractiveness of the MCC seems to have been exploited by a small group of opinion-shapers and hampered the operating environmen't to the extent of requiring changes in program design, no drastic alterations to the interior are recommended.

The Afghan refugees have been exposed to many services and ideas they never dreamed of before 1978. New uses of 
architectural spaces are among 'these; some reconstruction planners predict that once the refugees return home they will no longer be content with the dingy and shoddy public structures they were provided in the past. This facility serves as an outstanding example of how effectively low-cost, locally available materials can be used. Certainly providing children with a model for affordable healthful and attractive work places is a worthy objective. They will ultimately become decision-makers in their communities.

The second facility in nearby Mohammad Khoja was not being used by the MCC program at the time of the evaluation.

Activitie's with Women (Objective No. 3)

Not surprisingly, after an initial enthusiastic response, women ceased to attend the MCC, and they have been purposefully excluded since the opposing leadership insisted the MCC employ a middle-aged relative of one of Kahi's influential religious leaders as a "gatekeeper" (28 June). He is persunable and interacts well with the children, but he is strict in keeping women out.

A few female family members, of preteen girls attending the MCC were queried in their homes about the rumours which led to the ban on women. "The mullahs tell us so," they said, but then expressed disagreement and regrets. They described the uncomfortable, long waits at the BHU where they must sit in the open, crouched under their veils because 
of the arrogant comings and goings of men, even within the walled section intended for women only. They were also highly critical of the harassing manners of some of the male health monitors at the female BHU.

The sight of these huddled women strengthens the falsely stereotyped image of rural Afghan women as egoless nonentities, devoid of confidence and self-esteem. The refugee experience has been traumatic for all these women; some have been cruelly affected. The majority, however, are coping with admirable fortitude. The transformation which occurs once these seemingly anonymous creatures find themselves in all-female environments, such as the special feeding or demonstration rooms at BHUs, is remarkable. Eyes sparkle and intelligent, animated exchanges frequently take place as the quiet, the timid, the assertive and the charismatic interact, some jolly, some somber, some beautiful, others not so. Outstanding was one regal woman who carried herself with poised authority and enviable grace. Dignity is perhaps the most common characteristic of these women, as it is of Afghan women in general.

The following brief comments on a few cultural patterns explaining the striking differences between the outside/ inside images of these refugee women may be relevant to future programming for the MCC. They include:

1) women as symbols of honour

2) women as perpetuators of culture 


\section{Dupree - 6}

3) women's roles and responsibilities

4) women's networks

5) women's interactions within the family; i.e., family dynamics

First, women symbolize honour of the nuclear family, the extended family, the community, the tribe, the nation - and, in the immediate present, the jihad (resistance movement), which is being fought to preserve the very valued way of life the women symbolize. This heavy responsibility has defined the ideal feminine personality in Afghanistan throughout its history .

By extension, through their behavior women enhance or destroy the honour of all the above components. This explains the relative ease with which small groups of self-styled arbiters of proper behavior can restrict the activities of women, for the power of negative gossip is a paralyzing deterrent respected by both men and women. What other people may think is as important d's what actually happens. To prevent dangerous gossip, all association, even eye contact, with men outside the family is avoided in every way possible. Special cautionary measures are deemed necessary in the refugee camps because they are viewed as hostile worlds where women become vulnerable the minute they leave their homes and wherever they move about.

Secondly, women are perceived as the perpetuators of culture, for it is they who pass on the values of the society during the early education of children. During exile many alien influences threaten to adulterate the value system for 
which the jihad is being fought, again necessitating the imposition of stricter observances of protective institutions for women, such as purdah (seclusion), of which the veil is an integral part. Severe restrictions on mobility and activities are the result.

Many women were, and some are still, forbidden to attend BHUs; even primary schools for girls are anathama among some groups. Although these attitudes softened somewhat over the years since 1978, stricter attitudes seem to be returning as prospects for repatriation brighten. The future is by no means clear. Security will take time to establish. Leaders have yet to emerge. Ten years of an artificial existence may make a return to traditional ways difficult. The return seems as fraught with dangers as was the exodus.

Also, undercurrents of concern over the future place of foreigners 'swell as grandiosé schemes for Afghanistan's reconstruction are discussed in the world media and by NGOs in Pakistan. Some Afghans speak with sincere trepidation of the "cultural invasion" which may follow the retreat of Soviet forces. Reports that some cross-border leaders are insisting that there must be no programs for women may well reflect apprehensions that the honour of women will again be endangered as cultural values are threatened from new directions. The question of programing for women will remain a ginghly sensitive issue for some time.

Thirdly, even though the primary authority of men is 
unquestioned, male-female roles and responsibilities were closely interrelated in pre-1978 Afghanistan. Both men and women were aware that family welfare depended on these interrelationships and both derived mutual respect from this understanding.

Men plowed the fields, sowed the seed and harvested grains and vegetables; women baked the bread and processed the vegetables. Cotton, fruits and nuts were often jointly harvested. Women enjoyed these breaks in their domestic routines.

Once the harvests were in, men sold surpluses in the bazaars, but it was the women, usually the matriarchs, who managed the daily distribution of household stores, a crucial. responsibility: unless supplies lasted until the next harvest the family either starved or went into debt.

Women's handicrafts served as important economic contributions to offset marriage expenses and as ego-satisfying activities from which women derived status among peers and elders, particularly in-laws. Typically, this handiwork was seldom sold, except among specialized groups such as carpet weavers, for it was generally considered shameful to sell. work made by the hands of women.

In Pakistan there are no crops to harvest, few vegetables to process.' Only a minority can afford the raw materials for handicrafts, and the old stigma against receiving money for women's handiwork plagues some income-generating projects for women. It may well be that the demand for the closure of 
the Kahi handicrafts center, made during the dispute over the adjacent MCC, stemmed in part from such attitudes. Or, it may be that the men of Kahi simply objected to women being given the opportunity; for the first time, to earn independently, viewing this as yet another cultural intrusion undermining their authority.

Nevertheless, the successful evolution of incomegenerating projects for women in general among a wide variety of groups has interesting implications for the future. Many women are participating in income-generation, both as producers and managers, because there are many families in economic need. Both men and women consider this assistance to vulnerable families an extension of the jihad effort, and this honourable work. Whether extra-domestic earnings by women will continue to be accepted after the jihad ends is hard to predict. If it is, many vistas will open.

Be that as it may, in addition to being deprived of meaningful activities which once provided women respect and sélf-esteem, men are now frequently away for long periods, on the jihad or engaged in work in which the women have no part, and no understanding. A growing sense of marginalization, even when it is not articulated, often results in depression and accompanying physical ailments. Few outside resources are available to alleviate these feelings so women, more than ever, must depend on each other for support. Fourthly, extensive village women's networks functioned 
in pre-war Afghanistan, not only for informal socializing, but because few, and in many areas, no, institutionalized services existed. The family replaced government as the single most important institution, providing services for its members from birth through old age security. Many of these services were performed by women through networks which brought them together in a wide range of cooperative and supportive endeavours as leaders, as specialists and as recipients of assistance. These gatherings were group reenforcing, strengthened community cohesiveness and enhanced individual self-esteem. Furthermore, within these networks women were free to make their own decisions and moved without question. Services were generally reciprocal exchanges, although payments of small amounts of food stuffs or raw materials were occa'sionally made.

Among the refugees in Pakistan many of these networks have been eroded, but the vestiges fortify women, allowing them to develop positive relations with one another and conduct themselves with courage. Several settlement patterns aid women in maintaining networks. Wherever possible, tribally and/or kin related village units reestablished themselves. In Kahi, women from related households move from... one compound to another over low walzs via a series of ladders so as not to enter public spaces outside their compounds. These types of private communication systems were utilized in many parts of pre-war Afghanistan. 
Visiting is a vital part of life for Afghan women. Being alone is a grevious state. Women constantly come together, for work and play, in informal groupings determined by momentary needs or personal whims. Past attempts to formally "organize" women seldom succeeded, however. The Kabul leftist DRA (Democratic Republic of Afghanistan) regime's literacy campaigns, for instance, were repudiated in good part because unrelated women were forced to gather in centralized facilities.

Further, after the DRA takeover, education, whether for boys or girls, let alone women, came to be regarded as a path to Communism, the root of exile, and fell into utter disrepute. This intensified natural reservations about education, including the belief that schooling weakens the family support system. Gathering women in any manner which could be regarded, even remotely, for educational purposes is today totally unacceptable to many.

However, some changes have occurred on the refugee scene. Ockenden Venture's successful quilt-making center on the outskirts of Peshawar provides income for large numbers of refugee women and a kindergarten for their children. These families, however, tend to be more receptive, as a are most who had some contacts with urban Iife in Afghanistan before 1978 . Also, all-female food processing and ceramic factories had been an accepted part of the urban economy for some years prior to 1978 and the quilt center may be regarded as an extension of these patterns. 
BHUs in Pakistan, on the other hand, were novel to most rural Afghanis for health services seldom extended beyond urban centers. The benefits of the BHIs have been readily accepted. A few women are denied access, but for many a visit to a BHU is the only acceptable outing. By extension, educational programs clearly related to health have won almost universal approval. The most successful primary health programs for women have been those with outreach components utilizing mature local community workers responsible for small units of about 30 or so in related groupings living in contiguous housing. Because these units more closely replicate the traditional women's networks, the women feel more at home and are consequently more receptive.

Lastly, women's interactions within their families are another source of strength. A woman enhances her status by becoming a wife, then a mother, a mother-in-law, and finally a grandmother, the respected matriarch of the family. Girls commonly marry in their mid teens at which time they normally move to the groom's home. Here they seldom have any authority or influence until a child, preferably a son, is born, However, since cousin marriages are preferred, the move generally does not distance the girl too far from her own family with whom she maintains important contacts. Brother-sister bonds are particularly strong, supportive and protective.

The responsibilities of women in this tightly knit system vary with age and economic standing, two factors which also affect their mobility. older women move about more freely. 
Generally speaking, more affluent families maintain stricter purdah as a measure of status. Therefore, even though women in economically secure households exhibit superior leadership qualities, they seldom care to assume such roles. They may agree to participate, especially when asked to do so by outsiders, but often they are less effective than charismatic women from mid-range households. of course, there are always exceptions!

Young married women perform most of the daily household chores, and while still of childbearing age they seldom venture into the public sphere without a male escort. As the children multiply, the responsibility for their tending passes to older boys and girls, who are also given outside tasks at very young ages, such as grazing animals, fetching water and running errands in the bazaar. Afghan babies receive constant hands-on loving care, hugs and kisses, from children as well as adults; seldom are they left to themselves. Rural children, however, enjoy no adolescence, little time of learning away from the home, and are expected to shoulder responsibilities early.

Fathers teach boys trades, farming or herding as soon as they are physically able. Puberty marks the beginning of purdah for girls, and the end of free association with teen boys outside their families. Meeting family expectations by learning to execute household duties skillfully and preparing for motherhood are the primary options for girls in 
purdah seeking status and peer approval. They learn these skills at home, under the tutelage of their mothers, grandmothers and aunts, the primary educators in rural Afghanistan. usually are required to maintain discipline, for Afghan fathers are notoriously indulgent. In short, women are the major actors inside the compound where they are responsible not only for the physical well-being of the entire family and the skills-training of the girls, but for moral development as well.

The myriad tasks are shared between mothers, elder daughters, aunts and, at times, multiple wives who share work spaces even though they maintain separate private quarters. But the primacy of the role of the grandmother generation in child socialization should not be overlooked. Her voice is often more respected than that of the wife. She sees to many aspects of a child's upbringing, playing infant games, singing folksongs and recounting folktales replete with the wisdom of the ages and the belief system of the present. They pass on their experiences, often including a knowledge of gathering and preparing herbal medicines, an important contribution where health services are practically non-existent. She holds the keys to household stores and passes on household management skilis, but most importantly, she is the acknowledged source of love and security. Toddlers most prefer her lap and children are always gathered around her. 
In addition, she is allowed greater mobility, permiting her to act as a link between the secluded home environment and the outside world. When properly motivated these elder women make superb communicators. The $\mathrm{FCC}$ program might investigate the possibility of involving some mature women in their endeavours.

Some modifications in these pre-1978 patterns have been made over the years in Pakistan. Household living arrangements now have more variations. Although usually at least one adult male is present, the majority of young men spend up to three months, or more, fighting in the jihad. Refugee households therefore tend to contain more complex mixtures of kin-related women.

One may consist of several married daughters and their children living with a widowed mother, who, typically, will be very much in charge. Several of the daughters may also be widowed; the war has created an abnormal number of widows which will be a special problem during reconstruction. A widow with unmarried childran may maintain a separate establishment, but she will always be accountable to some male relative of her husband; her sons and preteen daughters will carry out chores outside the compound.

A second wife may run a household which includes her husband's first wife whose married children are elsewhere, together with numbers of middle-aged single or widowed female relatives. Sometimes as many as nime nuclear families of 
brothers and cousins will build a maze of low walls to set off private spaces inside high compound walls.

The variety is endless, but these examples illustrate how women now, more than ever, depend on family interactions for survival and courage. These women live closely together, they are naturally garrulous and they love to gossip. If one woman tries something new to overcome a problem, whether it involves hygiene, nutrition, sanitation or whatever, she will be closely observed by many women. If she is successful, the lesson will not be lost.

The MCC might consider some type of outreach involving these natural units among which knowledge can be exchanged without exciting those who distrust institutionalized programs for women. When asked, one household indicated a willingness to act as a focal point for a MCC program - "as long as it isn't every day!," quipped one charismatic aunt.

Staff restrictions discussed below would necessitate cooperative efforts with other outreach programs.

Activities with Children (Objective No. 2)

The MCC's work^ children is heartwarming.

Daily attendance during the time of the evaluation was around 50, ranging in ages from babies to about 10 or 12 . It is impossible to calculate the total number who may have visited the MCC since it opened, however, because many have come only once, or pass by sporadically. As far as I know, 
no attempts have been made to estimate the target population, so one can not tell what percentage of potential beneficiaries attend. Nor are there any attempts to keep attendance records. The organizers wish to avoid the impression that this is a formal program requiring obligatory or regular attendance or that it is in any way similar to day-care/kindergartens established by the Soviets in Kabul before and after 1978 which are now regarded as institutions created solely for the imposition of Communism.

It is also not clear what proportion of the children comes while they wait for relatives at the BHU, and how many come expressly to attend the MCC. The children come and go as they please, or as they are celled to go home. Some come early and stay until the center closes; some come for a short stay; some leave for short periods to carry out chores, and return. A handful of bright preteen girls attend regularly, except when they are needed at home.

Occasionally batches of 10 to 20 school boys burst upon the scene, brimming with energy. They do not create any disciplinary problems, but they do cause a lot of confusion as they compete for space with those engaged in less boisterous activities. They enjoy crayon drawing and paper cutting, but most like to play catch with rubber balls. These frequently bounce off the heads of those playing with puzzles or wooden houses, cradles, pull-trucks and other toys. No one seems to mind, but clearly an outdoor" play area is needed. It is still. 
not clear to me why the IRC administration is reluctant to allow the MCC to set up an outdoor playground. other NGOs in various camps have set up play areas without adverse effects.

It would be unkind to ban these school boys from the MCC. Traditional educational practices based on learning by rote and strict discipline make the regular and religious schools not only dull but intimidating. The relaxed, creative atmosphere of the MCC which allows these boys to do their own thing is a new experience which they obviously relish. Anyway, the attention span of the boys tends to be limited and they suddenly pick up their shoes and go, leaving ample time to the others.

Furthermore, the boys contribute by participating during primary health lessons and storytelling periods. A number are very expressive and more should be encouraged. If the stories these children tell could be recorded, valuable comparisions with traditional folklore already in the literature could be made. Oral traditions are vital in this nonliterate society because they are used for instruction, for perpetuating the ideals of the culture, for reenforcing codes of behavior, and for imparting a sense of history. All are functions of paramount importance in refugee situations.

Girls and preschool boys should also be persuaded to speak out to the group more frequently, but many are shy, especially when the older boys are around. Prompting children to speak out could be especially useful during health lessons. 
Instead of teaching solely with the aid of flip charts the children might be encouraged to explain what the pictures mean in their own words, and relate them to practices in their own households.

This suggestion came to mind one morning when one of: the girls excitedly pointed at a gruesome sketch of an emaciated baby and said, "My brother looked like that once and my father brought some ORS." "Now look!," she continued, holding up a bright-eyed healthy one-year-old. A discussion on how to prepare and administer ORS could follow, with the children being asked to tell about proportions and other details.

Simple demonstrations would help strengthen the teaching of good hygiene, eye-nose-ear care, nail clipping, treatment of simple wounds and insect bite infections, etc.

The MCC could also makè a valuable contribution by developing more effective visual learning aids suitable for children. Production lags plagued earlier efforts. How about trying simple black and white line drawn posters which the children could colour in and take home? These would fulfill a variety of useful purposes.

Regardless of what variety of health-related activities are tried, a schedule/curriculum complimentary to programs being carried out at the BHUs and with Female Community Health Workers (FCHW) would reenforce the educational value of all outreach programs. 
Hopefully, emphasis could be placed on remedies for improving simple skin problems. More than hand and face washing is involved, especially in winter. I asked doctors repeatedly what home remedies could be suggested to alleviate chapped and cracked skin on cheeks, hands and feet which are common among children throughout the refugee population. None could suggest anything other than Vaseline, widely available in the bazaars. Surely there must be somothing cheaper, some herbal medicine?

Considerable data on traditional medical practices and medicines were collected in the past. Reportedly one of the INGOs is now undertaking further research. The IICC could well benefit from investigating what information is available on traditional medicine, called dawa yunani or Greek medicine.

But I emphasize practical training for preteens here because boys and giri's usually come to the InCC with their" younger siblings. Six-year olds come with two-or-threeyear olds; some carry infants. They are used to caring for these children in their homes and do not regard the responsibility as burdensome. Many gestures of genuine affection were observed and a lot of time is spent in cuddling, kissing and reassuring their charges.

In short, these preteens have much to do with childrear=ing and a good deal of the well-being of the young depends on them. Also, they are the parents of tomorrow. Yet preteens have been largely overlooked by primary health education programs. 
I believe it is time to make sure they become fully involved, and that the MCC can make a significant contribution by designing a coordinated health program for preteens.

Primary health education is recognized as a premium priority in repatriation and reconstruction planning. The refugee population must be in the best possible health before they return if they are to withstand the hardships of rebuilding a largely devastated land, and, if the admiral health record with no major epidemics and negligible acute malnutrition is to be maintained. It will be some time before any large-scale repatriation takes place so there is some precious time left in which present training programs should be intensified and expanded. After the return it will be a long time before health services can be extended to provide adequate health systems. Paramedic training an all levels is another urgent priority therefore. Preteens are an untapped resource and should be included in this important campaign.

Other valuable contributions of the MCC involve building confidence and learning skills. Initially, newcomers are understandably shy. Normally they have very limited time or place for games. It is hard for them to comprehend a play area of their very own where they are encouraged to play instead of being scolded for frivolous behavior and for neglecting their duties. Never have they seen such a plethora of toys. Crayons are new. Sissors to play with? Hard to believe. All together it is an overwhelming experience to most and in the beginning many of the children prefer to stand 
and watch, afraid to try anything for fear they will fail and look ridiculous.

The relaxed and' cordial atmosphere created by the MCC staff dispels these anxieties. Thus, I was greeted with selfassured smiles and hearty handshakes. Within minutes the children took the initiative to involve me in their activities, vying with one another for my attention. These children have come to relish, one might almost say, crave, interactions with non-family members. Children in pre-war Afghan villages were normally curious, outgoing, sometimes cheeky, communicators. I sensed a deeper sensitivity and urgency among these children, however, which no doubt relates to the state of being a refugee without roots.

Being: involved directly in their activities, I ceased to be a mere observer and became a participant which allowed me to appreciate how alert they are and how quickly they learn. Colourful wooden puzzles are most popular. Novices see no relationship at first betwen the object in their hand and a space of a similar shape on the board, but they are able to master the concept after a few tries. Having become pros they pass on their new talents to the young and newcomers with a new sense of pride. These interactions are group-oriented and cooperative, with a lot of friendly sharing of space and materials. I did not feel any tension, nor did I witness any altercations. Afghan children in general are well disciplined. They also enjoy games, and perhaps a wider variety, both 
traditional and new, could be introduced. Bujul, a form of marbles using sheep's knuckle bones, is an example of a traditional game which is nondisrupting. Puppets have a tradition in Afghanistan and make most effective teaching aids.

I inadvertently invented a learning counting game one morning which illustrates how receptive these children are. One of the girls started her own idea of a game by piling dolls into my lap, and as others joined in with lots of laughter it became necessary to introduce a calming note. I called a halt, which was immediately obeyed; elders are always respected. To get the dolls off my lap and back into general circulation we began calling out for numbers and those giving the correct consecutive number received a doll; those who missed started from one and counted again, with lots of help and giggles from the others. Before long this group; of about 8 boys and girls were playing the game by themselves, content to allow me to sit on the sidelines for a welcome break.

Some girls want so much to be taught to read and write, scribbling make-believe Persian script and asking for corrections. I thoroughly appreciate the 'reservations concerning introducing anything that could possibly be construed as education for girls, but it is such a pity. I hope some gimmick can be found. Alphabet blocks in Perso-Pashto script, perhaps?

I did not observe the use of the map of Afghanistan displayed on the wall. Teaching history would be tricky, for it might be frowned upon by those looking to criticize. Geography 
Dupree - 24

should be safe enough. Perhaps those who have done such a creditable job in making wooden toys might be persuaded to make blocks in the shape of the provinces of Afghanistan which could be fitted together to build the nation.

These children have grown up outside their homeland and need to be given some sense of their own culture. Folktales, folksongs and traditional games can contribute. The emphasis the INCC staff places on sharing, respect for one another and elders, kindness and cooperation, strengthens their appreciation for the teachings of Islam, as do lessons on good hygiene.

There are many passages on hygiene in the Koran and the Hadith (Sayings of the Prophet MOhammad-PBUH) which could be used effectively in passing on an important part of their cultural heritage, while furthering health education at the same time. Indeed, the Koran describes a total way of life. Perhaps a collection of maxims particularly applicable for children, a lesson a day, if you will, would be appreciated.

A few handicrafts would add variety, especially for the older girls. I would think this could be introduced without fear of criticism, if the children make items they can take home and use themselves. In many families in Kahi embroidery and beading is already practiced as a highly refined art. Girls might find it enjoyable, however, to learn how to make simple clothing for the infants. Decorating hats with pompoms would be fun. Finger-weaving drawstrings for the gathered trousers everyone wears is another possibility. Or clay 
modeling. One morning on the way to the MCC we saw three small children making mud pies and dishes. Modeling animals out of clay would be more imaginative, and the clay could probabiy be procured from local potters already prepared for use. But perhaps this would be too messy for the staff; the children would love it.

One day a staff member held some older girls entranced while she made paper flowers and boats. I am sure both boys and girls would be thrilled to learn how to make these and toerh paper-folded objects in the rich oragami tradition.

I suggest the introduction of some variety precisely because the MCC has succeeded in providing these children with a place of their own and novel opportunities for learning how to play while utilizing their own imaginations instead of following set activities prescribed and led by adults. Now that they have gained confidence through these experiences I sense the children will soon ask for more. They are so bright and I predict they will demand continuous stimulation.

The children who come to the MCC attend because they have the courage to enter, even though timidly at first. It is the many, too many, children traumatized by war and the refugee experience who would most benefit from the program, but they are not easily found. Perhaps the FCHW program could develop a component to raise awareness of the special needs of withdrawn and troubled children so that they could be referred to the IMCC as part of an outreach program. Dr. Mohammad Azam Dadfar, Director of the Psychiatry Center for Afghans, tel. 42987 in Peshawar, could be helpful in designing an awareness 
program.

Now that the MCC program has established a smoothly functioning preliminary format, I strongly suggest compiling more complete profiles of the socio-economic background of children attending the MCC so that future program development may reflect a closer observation of the needs and problems of the children. This would be particularly urgent should either preteen health education or outreach programs be considered.

I do not suggest a systematic survey and I am strongly opposed to questionnaires. Non-literates, are suspicious of note-takers and answer as they think they should, which often has nothing to do with the truth, or purposefully falsify information.

Much valuable information flows naturally out of casual conversations with the children. As mentioned previously inany seemed hungry for one-on-one interactions will :l: MCC staff, although these sessions seldom remaj:1. for very long since others were so eager to be includet. This enlarges the scope of information. $\Lambda$ good deal is aldotij known, but it has not been recorded in a meaningful way. Key areas of information would include ethnic groüp and geographic area of origin, with note of any." proximity to ur.ban centers. Those who have had contact with urban ways are often more receptive to new ideas. Economic and occupational s atus would be interesting. Do any children from 
nullah families attend? Dress styles of women attending che BIU indicatied to me that therr inust be numbers of women rom urban areas, or from affluent rural families, some of thom may be non-pushtun. Are theso fanilies represented at he MCC? Is there any corteliation between economic or occuational status and a child's receptiveness and rate of evelopment?

Knowing the marital status of mothers and other female tembers in a household, and whether they engage in handirafts, would help in determining support networks and the ossible impact of any outreach or preteen programs. Knowng the number of male family mombers in the Kahi household, nd their relationship to and status in the jihad would nfluence outreach plarming.

For example. A hastily noted background profile sheds ight on the reason why one particular preteen girls is selfssured and confident. Her extended family lands are located n a rural area south of Kabul, but her father purchased land utside Kabul where he was stationed in the airforce. Thereore she belongs to the rural. elite with exposure to education nd urban life and their acceptance of the MCC is understandable. n Kahi, they live in a large compound close to the ince so $t$ is easy for her to attend almost dajly. Her mother is the ominant fiemale member in her household which includes her ive children, one a male toddler, her husband's first wife, nd an assortment of aunts, all of whom were dressed in 
heavily beaded and embroidered silks. The father, now a commander in the jihad, has been away for over six months. These commanders will maintain status after repatriation and they wijl. help determine the direction of reconstruction in their areas. This preteen girl therefore will move into a position of status within her women's networks.

Staff (Objective No. 4)

The Coordinator has adeptly redesigned the proposed program and established a new format which has the potential of opening up a significant new dimension for non-formal education in Afghanistan.

The Assistant Coordinator is totally dedicated to the project and is responsible for maintaining the warm and loving atmosphere the children so obviously enjoy. She is so atuned to the children that she is able to shift activities and introduce new ones in order to keep the momentum moving throughout the day, no matter how many children are present or what the mix may be. She is equally effective when making home visits, blending in as though she was a member of the family. Her rapport will facilitate the compilation of socio-economic profiles essential for the next phase.

Three young assistants also interact well with the children and conduct the health and storytelling periods competently. No complaints against the staff have been voiced, and the fact that they are warmly welcomed in the homes underscores their acceptance by the community at large. 
Attempts to hire more staff have been unsuccessful. No women living in the Hangu area are interested and interested women in Peshawar are not permitted to work so far away despite the protective living arrangements provided by IRC. All projects concerned with women's programs are plagued by the fact that family members refuse to allow women to stay away from home overnight.

It may be possible to involve older women, grandmothers, for example, in some cooperative outreach projects but the objective of developing para-professional early childhood case workers in the rural areas is not culturaly realistic. This should be reserved for urban situations where I predict there would be an enthusiastic,positive response. Such a response might also be expected in closely' related ethnic or king groups in a specifically designated sector of a refugee camp.

\section{Why is the MCC needed?}

Some question the need for a program for young refugee children. In addition to the potentials discussed above, I should like to state that these children represent the future of Afghanistan. Some have experienced the horrors of war; all hear tales of man's inhumanity to man repeated endlessly. All suffer from a sense of rootlessness of refugee displacement. In order to rebuild a peaceful, prosperous Afghanistan more 
Dupree - 30

than mere technical know-how is needed. Children must learn there is more to life than war and the jihad. They must experience the meaning of the Islamic teachings that men must respect one another and that cach is responsible for the wellbeine of his neighbour. The MCC is not just a play house.

As just one measure of the success of the MCC approach it may be mentioned that the art work of these children does not include the war scenes filled with helicopters and tanks, the dead and dying, the destruction of man and ecology depicted in most of the art work by students in schools run by the political parties in Peshawar. Here the children use motifs from traditional handicrafts and everyday life, including animals, houses, mosques, birds, trees and flowers. 


\section{MAJOR SUGGESTIONS}

No alterations to interior of the MCC

Page

Involvement of mature women; grandmothers

Outreach program with extended family units

Outdoor play areas

Recording of stories told by children

Promotion of participation by children in storytelling and health lessons

Simple' health demonstrations

Effective visual learning aids development;

colouring health posters

Complimentary schedule/curriculum designing with

BHU and FCHW outreach programs

Search fo home remedies for skin problems

Investigation of current research on traditional
herbal medicines

PRACTICAL HEALTH EDUCATION/TRAINING FOR PRETEENS

New games

Puppets as teaching aids

Basic literacy; Perso-Pashto alphabet blocks

Map puzzle

Collection of Islamic maxims applicable to children

Introduction of handicrafts: sewing; finger-weaving; clay modelling; paper folding

Awareness program for traumatized children;
referrals

Socio-economic profiles 